\title{
Widening inequalities in premature mortality in Australia, 2006-16
}

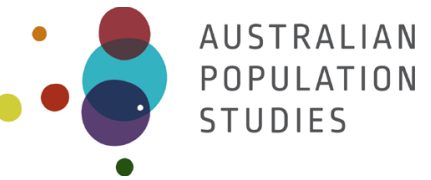

Tim Adair* The University of Melbourne

Alan D Lopez The University of Melbourne

* Corresponding author. Email: timothy.adair@unimelb.edu.au. Address: Melbourne School of Population and Global Health, The University of Melbourne, Level 5, Building 379, 207 Bouverie St, Carlton 3053 VIC, Australia.

Paper received 13 December 2019; accepted 11 May 2020; published 25 May 2020.

\begin{abstract}
\section{Background}

Increases in Australia's life expectancy have slowed since 2003. Within this context, it is important to analyse whether socio-economic and geographic inequalities in premature mortality have changed in recent years.
\end{abstract}

\section{Aim}

The aim is to measure the extent of and change in inequalities in premature mortality (under 75 years) by area socio-economic status and remoteness in Australia from 2006-16.

\section{Data and methods}

This study uses Australian death registration data from 2006-16. We identify area socio-economic quintile (Q1 lowest to Q5 highest) and remoteness (major cities, inner regional, outer regional/ remote/very remote) for each decedent. Age-standardised death rates (ASDR) at ages 35-74 and 0-34 years are calculated and smoothed over time.

\section{Results}

ASDR decline at ages 35-74 years has slowed markedly, and from 2011-16 Q1 ASDRs stagnated. The Q1:Q5 ASDR ratio for females rose from 2011-16 for males (1.97 to 2.11) and females (1.78 to 1.98), and also widened in the Q2:Q5 and Q3:Q5 comparisons for females. ASDRs outside major cities stagnated from 2011-16 and inequalities compared with major cities widened to be $40 \%$ higher in 2016. ASDR declines at 0-34 years were quicker than for 35-74 years and inequalities widened slightly.

\section{Conclusions}

Slowing declines in premature mortality in Australia are accompanied by substantial and widening socioeconomic and geographic inequalities. Without reductions in mortality in lower socio-economic groups and outside capital cities, future life expectancy growth in Australia will likely be hampered.

\section{Key words}

Mortality, premature mortality, inequalities, socio-economic, Australia. 


\section{Introduction}

From 1970 to the early 2000s, Australian life expectancy increased more rapidly than most other highincome countries to become among the highest in the world (Lopez and Adair 2019a). This trend was primarily driven by large declines in mortality from cardiovascular diseases and other causes strongly related to smoking (Taylor et al. 2006, Adair et al. 2011, Taylor et al. 2012). However, since 2003 Australia's life expectancy gains have slowed, both compared with preceding decades but also to other high-income countries, largely due to slowing mortality decline among males aged 45-64 and from deaths due to cardiovascular diseases (O'Flaherty et al. 2012, Hayes et al. 2017, GBD 2017 Mortality Collaborators 2018, Lopez and Adair 2019a, Lopez and Adair 2019b). Indeed, since 2013, life expectancy for both males and females in Australia has stagnated.

Investigation of the reasons for slowing mortality decline typically focuses on identifying the contributions from specific age groups, birth cohorts, causes of death, and risk factors. While such analyses can be very informative, it is also possible that inequalities in mortality risk according to socioeconomic status or place of residence have widened, with slowing declines or even increases in mortality rates in some population sub-groups being sufficient to prevent continued improvements in overall life expectancy. For example, in the USA, where the slowdown in life expectancy has been particularly acute, and has not increased for males since 2010, inequalities in life expectancy by county and education have widened; indeed, life expectancy at birth has declined in a number of counties since 1980 and adult mortality rates have increased among low-educated whites (Case and Deaton 2015, Dwyer-Lindgren et al. 2017, GBD 2017 Mortality Collaborators 2018).

In Australia, previous analyses have focussed on mortality inequalities by socio-economic status and place of residence. Analysis across all ages in 2015 revealed that people living in the lowest socioeconomic quintile areas had age-standardised mortality rates almost $50 \%$ higher than those living in the richest quintile areas (Australian Institute of Health and Welfare 2018). Another study of mortality at 20 years and over from 2001-07 showed the relative risk of mortality to be $88 \%$ higher in the lowest versus highest individual income quintile, compared with $32 \%$ higher in the equivalent area socioeconomic quintile. The same study also showed 63\% higher mortality risk for those with 12 or less years of education versus those with more than 12 years (Clarke and Leigh 2011). Mortality differences according to individual education level were even higher. Based on registered deaths at ages 25-84 years in 2011-12 linked to 2011 census data, mortality rates of males who had not completed Year 12 nor post-secondary education were $120 \%$ higher than those who had completed a Bachelor's degree or higher, and for females were 64\% higher (Korda et al. 2019). By region of residence, people living in very remote areas had mortality rates $40 \%$ higher than those living in capital cities, 30\% higher than those living in remote areas and $20 \%$ higher than people living in outer regional areas (Australian Institute of Health and Welfare 2018). Earlier studies had shown that both area socio-economic and regional inequalities in mortality were higher under age 65 years than at older ages (Draper et al. 2004, Australian Institute of Health and Welfare 2014, Korda et al. 2019). Inequalities in life expectancy between Indigenous and non-Indigenous Australians were particularly large, being 10.6 years for males and 9.5 years for females in 2010-12 (Australian Institute of Health and Welfare 2018).

Less has been written about trends in inequalities, despite the obvious policy relevance and concern about the impact of social and economic policies and structural changes in society. From 1986 to 2002, 
annual declines in what has been defined as 'avoidable mortality' were greater in higher (5.0\% per annum) than lower socio-economic groups (3.5\% per annum), contributing to widening inequality in survival (Korda et al. 2007). Cardiovascular disease mortality declines from 1979-2006 were slightly quicker in higher than lower area socio-economic quintiles (Page et al. 2012). Not all evidence points to widening health inequalities, however: a study of life expectancy differences by area socio-economic quintile in New South Wales over the period 2001-2012 found no increase in the relative advantage of the better off (Stephens et al. 2017). Trends in health and mortality inequalities in Australia in recent years are of considerable interest given the widening inequalities in wealth, and to a lesser extent, income, that have been reported since the early 2000s (ABS 2019). Notably, multi-country analysis has revealed that country-level cardiovascular disease mortality increases with greater income inequality, controlling for socio-economic factors (Dewan et al. 2019).

In the context of this slowdown in life expectancy increases, and widening inequalities in wealth and income, it is informative to investigate whether inequalities in mortality rates have widened or not over the past decade or so since 2006. This study uses Australian death registration data from 2006 to 2016 to analyse trends in inequalities in premature mortality, taken here to refer to deaths under the age of 75 years, given that the literature review showed that these are the ages where slowing mortality decline is most pronounced and where inequalities are greatest. Inequalities are measured by area socio-economic status, remoteness, area socio-economic status within major cities, and remoteness within states.

\section{Data and methods}

Data for this study were extracted from the Australian Cause of Death Unit Record File (COD URF). The COD URF is a de-identified dataset of all deaths registered in Australia (Australian Coordinating Registry 2019). The dataset comprises death records collected by each State and Territory Registry of Births, Deaths and Marriages and the State and Chief Coroners through the National Coronial Information System (NCIS) and compiled by the Australian Bureau of Statistics (ABS) (Australian Coordinating Registry 2019). The COD URF is maintained by the Australian Coordinating Registry (ACR) based at the Queensland Registry of Births, Deaths and Marriages. Ethics Approval for the study was provided by the University of Melbourne Medicine and Dentistry Human Ethics SubCommittee (Ethics ID 1953560).

We extracted COD URF data for deaths registered between 2006 and 2017, and which occurred between 2006 and 2016; all analyses were conducted according to year of death occurrence. We did not analyse deaths that occurred in 2017 nor deaths by year of registration because of an unusually high number of late registrations in late 2017; that is, there was a sharp decline in the number of deaths reported to have occurred during October to December 2017 compared with what would be expected based on the number of deaths in the preceding nine months of that year. As a result, there was a much lower number of deaths registered in 2017 than in preceding years.

The COD URF contains information about the characteristics of the death and decedent (Australian Coordinating Registry 2019). This includes the age at death, sex, place of usual residence and cause of death, but no socio-economic information about the decedent. Place of usual residence was reported according to Statistical Local Area (SLA) for deaths with registration years 2006-10 and for 
Statistical Area Level 2 (SA2) for deaths with registration years 2011-17 (ABS 2006, ABS 2016). Deaths can be linked using SLA or SA2 level to area-level socio-economic indicators and geographic indicators. We used the ABS's Socio-economic Indexes for Areas (SEIFA) Index of Relative SocioEconomic Advantage and Disadvantage (IRSAD) as the area-level socio-economic indicator (SEIFA) (ABS 2008, ABS 2013b) The IRSAD is constructed from census variables covering income, education, housing and employment status. The ABS produce other measures of area-level socio-economic indicators, including the Index of Relative Socio-Economic Disadvantage (IRSD), but it is recommended to use the IRSAD in studies which seek to take into account residents experiencing advantage as well as those experiencing disadvantage, rather than just disadvantage (ABS 2013b). Given that we are measuring mortality experience of all decedents in each area (i.e. those experiencing advantage and disadvantage), we believe that IRSAD is an appropriate measure. We used the IRSAD scores to derive IRSAD quintiles of equal total population size. Quintile 1 (Q1) refers to the population with the lowest socioeconomic status as defined by IRSAD, while Quintile 5 (Q5) denotes the population with the highest socioeconomic status as defined by this measure.

The ABS releases a new version of the IRSAD after each census. Recent IRSADs include 2006, which is measured at the SLA level, and 2011, which is measured at the SA2 level (ABS 2008, ABS 2013b). We hence use IRSAD 2006 for deaths with registration years 2006-10 where usual residence of the decedent was available for SLAs and IRSAD 2011 for deaths with registration years 2011-17 where usual residence was available for SA2s. The IRSAD 2006 and 2011 are derived from different censuses and are also based on different variables (21 variables in 2006, 25 in 2011). Additionally, there were approximately 1,400 SLAs in Australia during 2006-10 and approximately 2,100 SA2s in 2011-17, so it is highly likely that an increase in the number of areas, and corresponding reduction in population size per area, would increase the likelihood that the IRSAD quintile would be the same as IRSAD if it theoretically was measured at the individual level. Therefore, it is very possible that inequalities in mortality measured according to IRSAD would widen from the SLA-derived (2006) to the SA2-derived (2011) measure, even if true inequalities did not. Hence, IRSAD 2006 and IRSAD 2011 are not directly comparable and so trends in mortality by IRSAD can only be analysed separately for the period 200610 and 2011-16. (Norman et al. 2016, ABS 2013b). However, these analyses will still provide valuable insights into trends in inequalities in mortality from 2006-16.

A new statistical geography was released by the ABS in 2016 which includes additional SA2s. We used ABS correspondence files linking 2011 and 2016 SA2s to determine the IRSAD 2011 for each new SA2 (ABS 2016). Many new SA2s were wholly derived from a single original SA2. However other new SA2s were derived from multiple original SA2s. For these new SA2s the IRSAD decile was that which comprised the highest proportion of the population based on a calculation of the IRSAD decile of each original SA2 weighted by the fraction of the new SA2's population that was derived from each original SA2. IRSAD 2016 is also available however it is measured based on the new SA2s, and because 2011-15 mortality data are based on the original SA2s then IRSAD 2011 is more appropriate to measure area socio-economic status over the period of analysis (ABS 2018a).

We also analysed geographic inequalities in mortality using the ABS remoteness classification, which classifies areas as major cities, inner regional, outer regional, remote or very remote. The 2006 version of remoteness is measured for each SLA; however, the 2011 and 2016 versions of remoteness are measured at the SA1 level (i.e. smaller areas than SA2) (ABS 2011, 2013a). The ABS 
has not published populations for SA1s, so we cannot calculate the 2011 and 2016 versions of remoteness at the SA2 level. We hence used the 2006 version of remoteness for all years of analysis. We used ABS correspondence files to convert remoteness from SLA to SA2 by calculating the percentage of each SA2 population classified as each remoteness category (weighted by the populations of the SLAs from which each SA2 was derived from), and categorising remoteness for each SA2 as its largest remoteness category (ABS 2011). As with IRSAD, we used SA2 2011-2016 correspondences to categorise remoteness for new SA2s. We conduct our analyses for the following groups: major cities (70\% of population during 2006-16), inner regional (19\%), and outer regional, remote and very remote combined (11\%).

Additional analyses were conducted by IRSAD within major cities. Three IRSAD groups were used: the four lowest IRSAD deciles (grouped based on all Australia), the 5 th to $7^{\text {th }}$, and 8 th to 10 th. To provide more geographic specificity, we also analysed mortality by state/territory and remoteness. In WA and SA outer regional, remote and very remote were combined, and we did not disaggregate Tasmania, ACT and NT. Population data were obtained from the ABS (2018b).

Death rates were analysed for two age groups - 0-34 years and 35-74 years - in order to distinguish between ages where non-communicable diseases are particularly prominent and those where injuries, infectious diseases and childhood diseases are relatively more common. Deaths within each age group were age-standardised using the Global Burden of Disease population age standard (GBD Mortality Collaborators 2017). Age-standardised death rates (ASDR) for data from 2006-16 (including for all mortality) were smoothed over time using localised polynomial smoothing with Stata 15.0 (Fan \& Gijbels 1996, StataCorp LP 2017). Localised polynomial smoothing of ASDR trends for the periods 2006-10 and 2011-16 provided unstable results, so a linear regression of ASDRs with covariate of year was used instead. All results are presented with $95 \%$ confidence intervals and all charts present ASDR point estimates.

Ratios of smoothed ASDRs were calculated with the reference category being that with the lowest ASDR, again with $95 \%$ confidence intervals. For the state and remoteness analysis, the ratios were calculated compared to the ASDR for all Australia for that sex. For each category, we also measured the annualised rate of change in smoothed ASDR during the period 2006 to 2011 (or 2006-10 where IRSAD is used) and 2011 to 2016.

\section{Results}

\subsection{5-74 years: area socio-economic quintiles}

The decline in ASDRs at ages 35-74 years in Australia has slowed markedly, from $1.9 \%$ per annum in 2006-11 to 1.0\% in 2011-16 for males, and from 1.6\% to 1.0\% for females (Table A1 - see Appendix). During 2014-16, there was even a stagnation in male ASDRs. Over the more recent period 2011-16, the ASDR at these ages did not change at all for males nor females in Q1, the lowest socioeconomic group (Figure 1, Table A2). From 2011-16, inequalities in mortality have widened for the lowest socioeconomic group compared with the highest socioeconomic group for males (1.97 to 2.11, or $14 \%$ ) and females (1.78 to 1.98 , or $26 \%$ ); that is, for each sex, people living in the lowest area socioeconomic quintile had premature mortality rates twice as high as those in the highest quintile. There 
was also a widening in the Q2:Q5 and Q3:Q5 comparisons for females, and this caused them to reach approximately the same level in 2016 as the respective ratios for males. During 2006-10, inequalities based on IRSAD 2006 were much narrower than for 2011-16 that was based on IRSAD 2011, and there was no clear increase in ASDR ratios for males while increases for Q1:Q5, Q2:Q5 and Q4:Q5 for females. It should again be emphasised that mortality by area socio-economic quintile in 2006-10 and 2011-16 are not directly comparable.

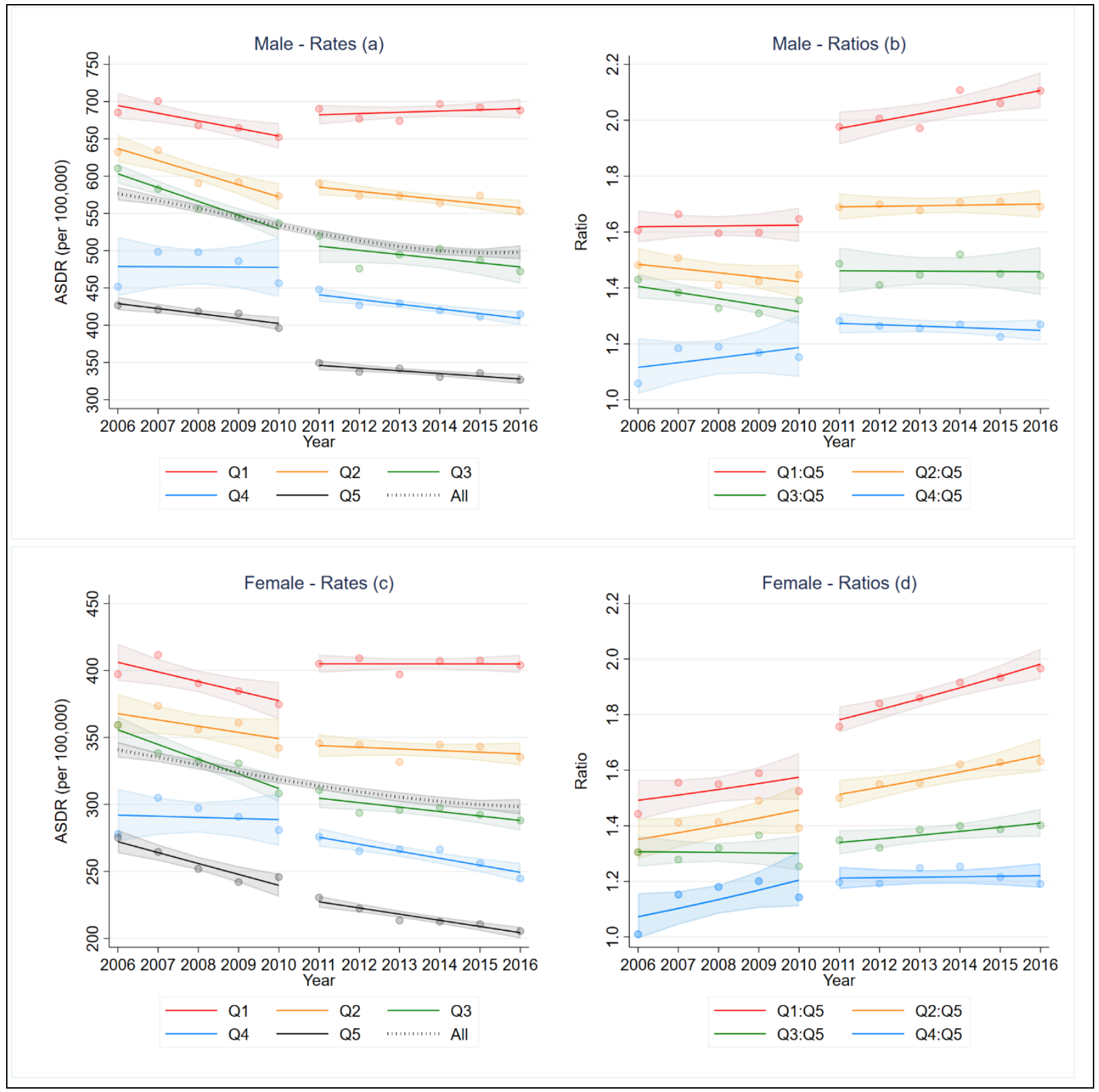

Figure 1: ASDR (per 100,000) by sex and area socio-economic quintile: trends and ratios (versus Q5), 35-74 years, Australia, 2006-10 and 2011-16

Source: ABS; author's calculations

Notes. Shaded area is 95\% confidence interval. Dots are point estimates. 2006 and 2010 measured using IRSAD 2006, 2011 and 2016 measured using IRSAD 2016. 2006 and 2010 results cannot be directly compared with 2011 and 2016 results 


\subsection{5-74 years: remoteness}

ASDRs for the population living in outer regional, remote and very remote areas of Australia were 40\% higher in 2016 than for the population living in major cities, and this excess mortality has been rising since 2006, more so for women (Figure 2, Table A1). This is due to declines in mortality at ages 35-74 years being more evident in the major cities (2011-16 1.3\% per annum decline for males and $1.4 \%$ per annum decline for females) than inner regional, outer regional, remote and very remote areas in recent years, where there has been no clear decline.
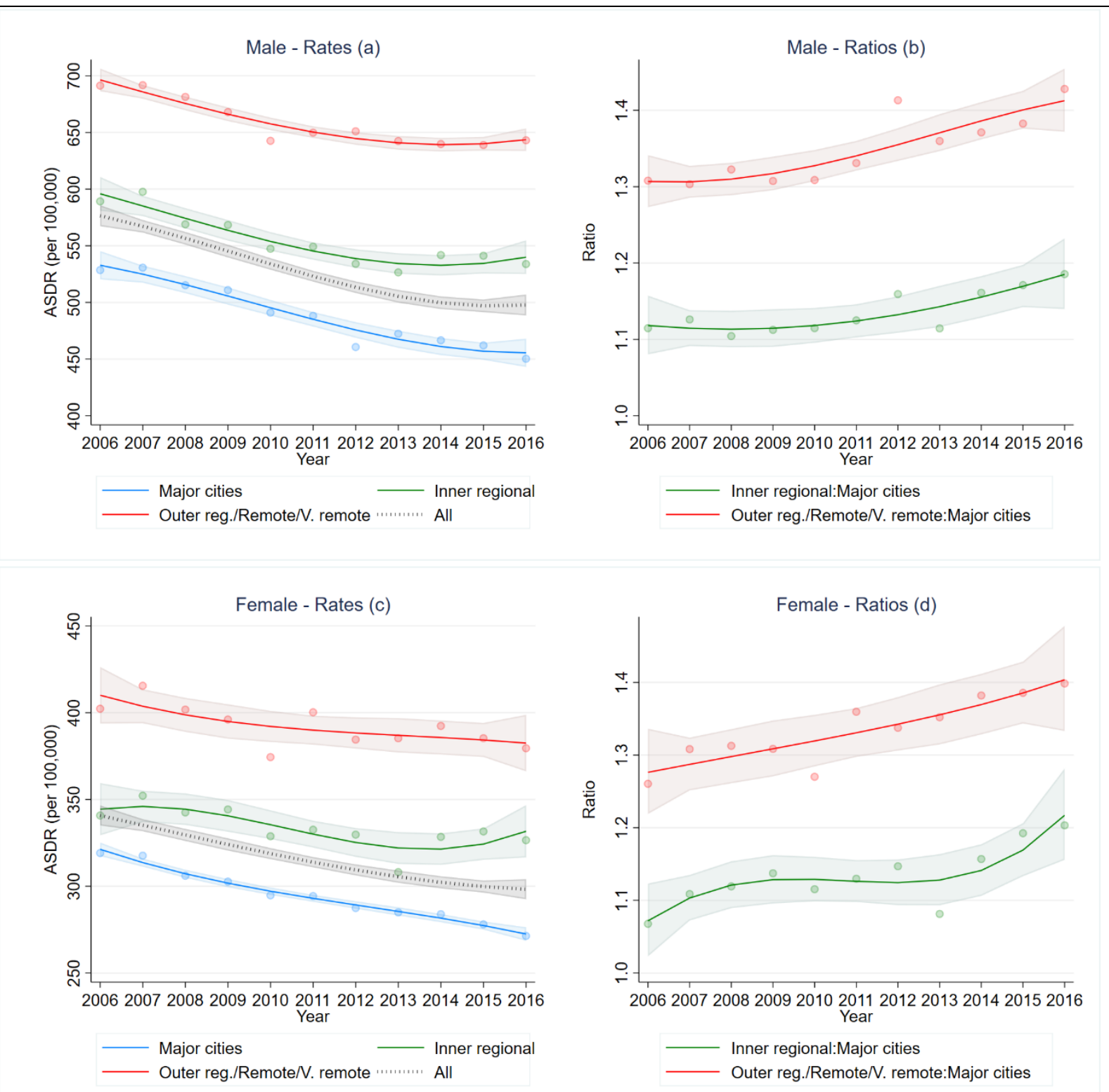

Figure 2: ASDR (per 100,000) by sex and remoteness: trends and ratios (versus Q5), 35-74 years, Australia, 2006-16

Source: ABS; author's calculations

Notes. Shaded area is $95 \%$ confidence interval. Dots are point estimates. Outer reg.: Outer regional. V. remote: Very remote. 


\subsection{5-74 years: Major Cities - area socio-economic deciles}

For the population living in capital cities, inequalities in mortality have increased slightly during 201116, after being steady or declining slightly in 206-10 (Figure 3, Table A2). The ASDR ratio was $79 \%$ higher for males and 70\% higher for females in the 1-4 (lowest socio-economic status) versus 8-10 (highest) deciles, and about one-third higher for both sexes in the 5-7 (middle) versus 8-10 deciles. Notably, the annualised decline in ASDRs for the population in deciles 1-4 was very slow during 201116 for both males and females, while there was no slowdown in the rate of mortality decline in the highest deciles.

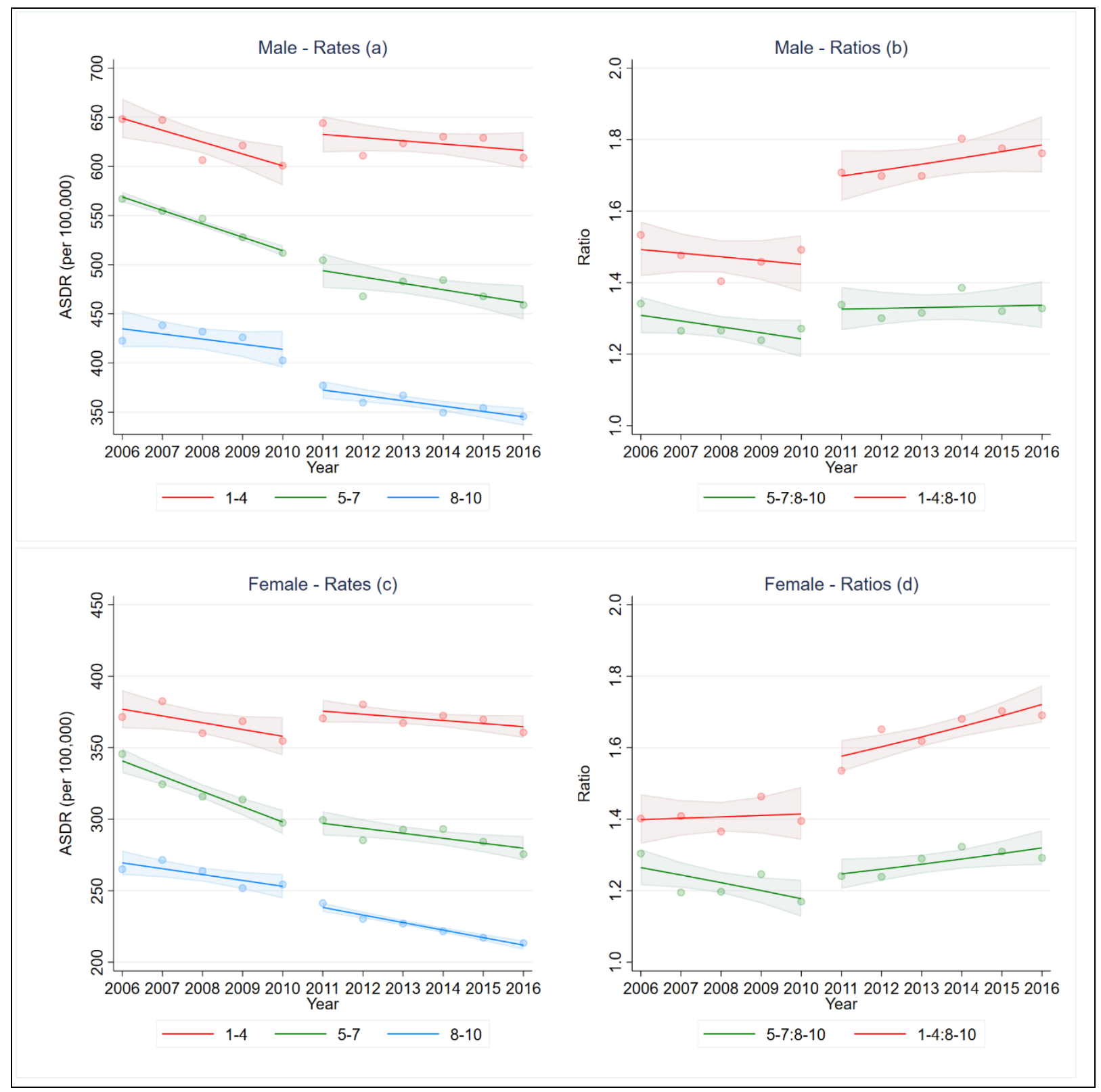

Figure 3: ASDR (per 100,000) by sex and major cities area socio-economic decile group $(1-4,5-7,8-10)$ : trends and ratios (versus 8-10), 35-74 years, Australia, 2006-10 and 2011-16

Source: ABS; author's calculations

Notes. Shaded area is 95\% confidence interval. Dots are point estimates. 2006 and 2010 measured using IRSAD 2006, 2011 and 2016 measured using IRSAD 2016. 2006 and 2010 results cannot be directly compared with 2011 and 2016 results. 


\section{4. $35-74$ years: State $\&$ remoteness}

Significant inequalities in premature mortality also exist by state and remoteness. Major cities in NSW, VIC, QLD and WA, as well as the ACT, had the lowest ASDRs (Figure 4). Conversely, the highest excess mortality compared with the national average was reported for the NT (ratio compared to Australia in 2016: 1.58 for men and 2.01 for women), Hobart, and NSW and QLD outer regional, remote and very remote areas (Table A1). Over the decade from 2006-16, there was a noticeable widening in the ASDR ratio in many locations in Australia, notably NSW outside major cities (males and females), VIC outside major cities (females), QLD Inner regional (males and females), SA outside major cities (males), WA outside major cities (males), and TAS (males), while there was a narrowing for NT males.

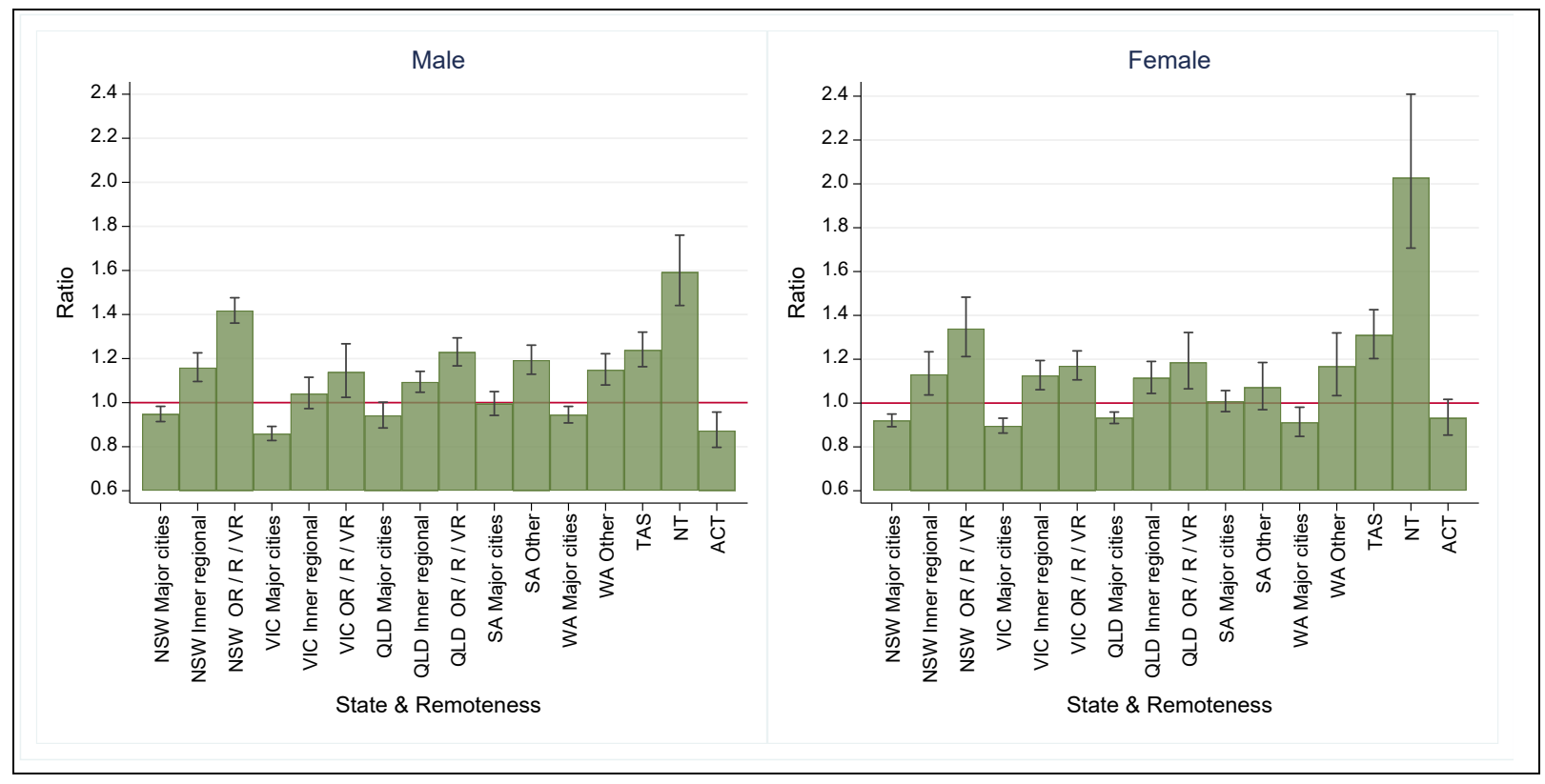

Figure 4: Ratio of state \& remoteness ASDR to Australia ASDR by sex, 35-74 years, Australia, 2016

Source: ABS; author's calculations

Notes. Capped vertical line is $95 \%$ confidence interval. OR: Outer regional. R: Remote. VR: Very remote.

\subsection{0-34 years: area socio-economic quintile}

While the vast majority of deaths in Australia now occur beyond age 35, with comparatively low levels of child mortality, inequalities in survival chances for children and young adults should be a policy priority. In Australia, declines in ASDRs at ages 0-34 years were quicker than at 35-74 years, being 2.2\% per annum for males from 2011-16 and 2.9\% per annum for females (Figure 5, Table A4). ASDR ratios Q1:Q5 and Q2:Q5 at ages 0-34 years in 2016 were only slightly wider than for adults aged 35-74 years after being somewhat higher in 2011, because there had not been the clear widening in inequalities as found for 35-74 years. 

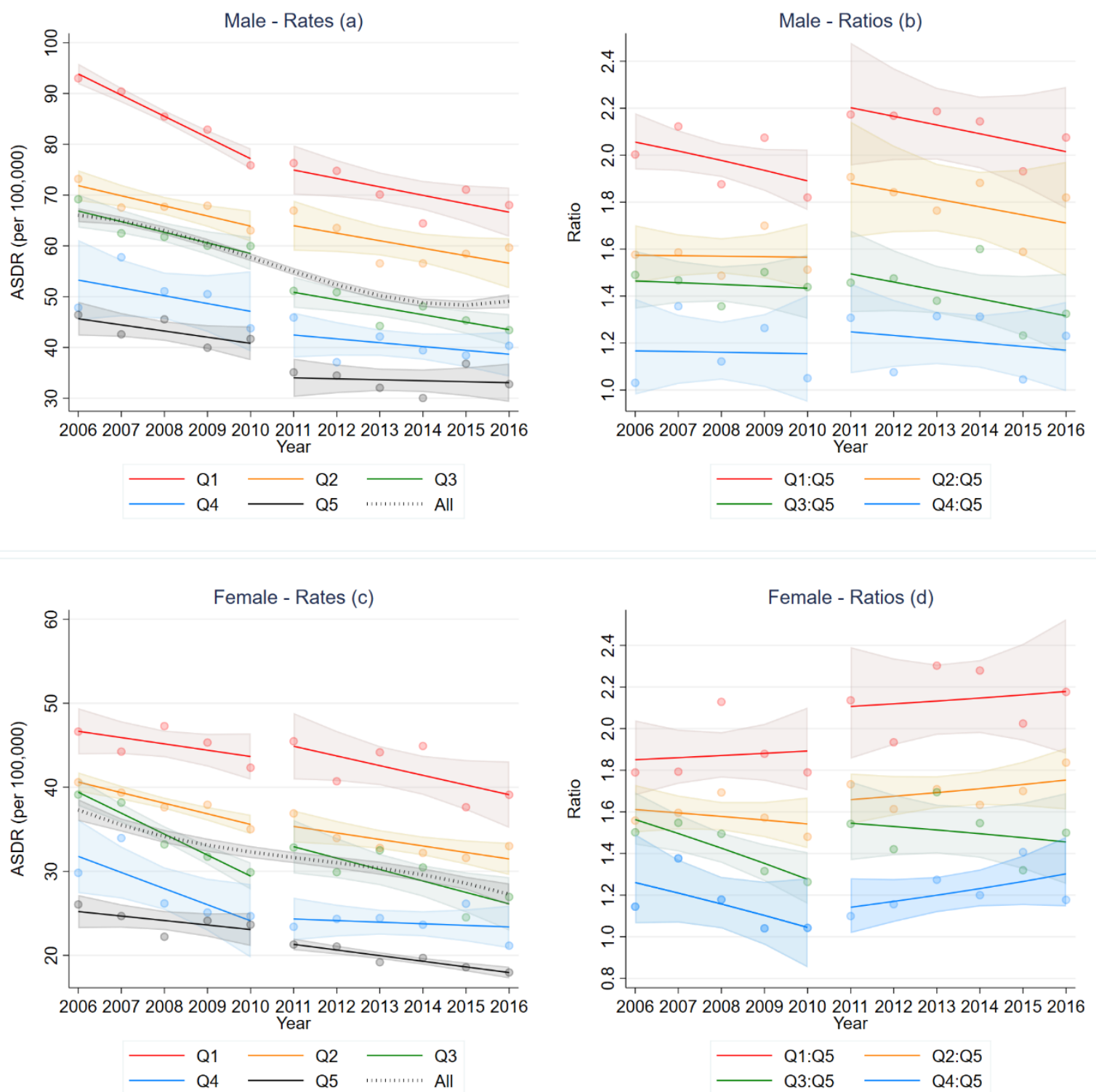

Figure 5: ASDR (per 100,000) by sex and area socio-economic quintile: trends and ratios, 0-34 years, Australia, 2006-10 and 2011-16

Source: ABS; author's calculations

Notes. Shaded area is 95\% confidence interval. Dots are point estimates. 2006 and 2010 measured using IRSAD 2006, 2011 and 2016 measured using IRSAD 2016. Ref.: Reference category.

\section{6. $0-34$ years: Remoteness}

Outer regional, remote and very remote areas have a much higher ASDR ratio versus major cities at ages 0-34 (1.79 males, 2.04 females) when compared with 35-74 years (1.41 males, 1.40 females) (Figure 6, Table A3). A similar differential is also found for inner regional areas. For females, the outer regional, remote and very remote to major cities ratio widened from 1.65 to 2.04 and inner regional to major cities ratio from 1.38 to 1.58 over the period, due to very quick declines in mortality in major cities. Male inequalities did not exhibit a consistent trend during the period and the net change was small, especially when accounting for the wide $95 \%$ confidence intervals. 

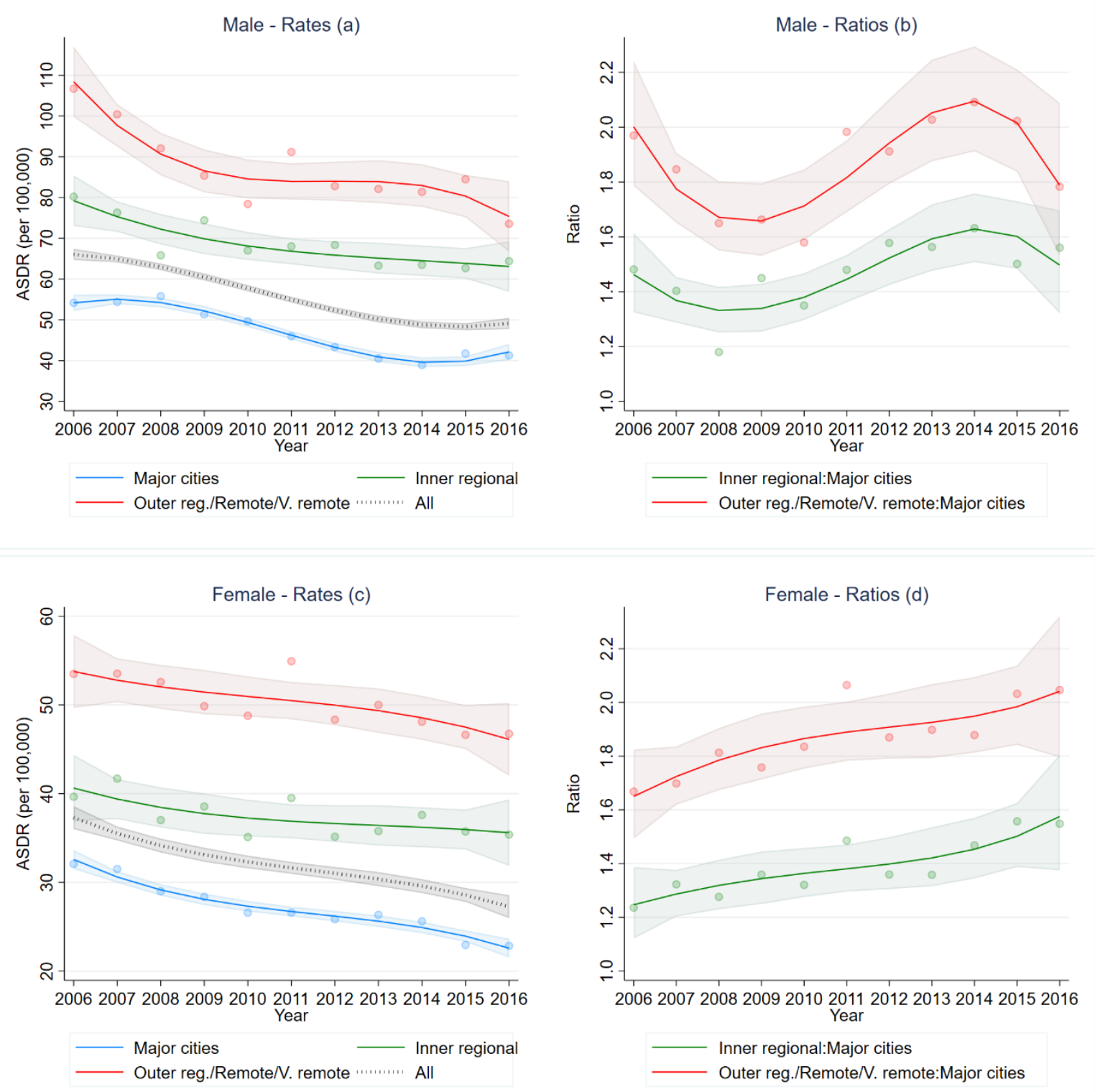

Figure 6: ASDR (per 100,000) by sex and remoteness: trends and ratios, 0-34 years, Australia, 2006-16 Source: ABS; author's calculations

Notes. Shaded area is $95 \%$ confidence interval. Dots are point estimates. Outer reg.: Outer regional. V. remote: Very remote.

\section{Discussion}

Australia has enjoyed very substantial declines in mortality since the early 1970s, largely due to the impact of public health policies to control major cardiovascular diseases, chronic respiratory diseases and other smoking-related causes (Lopez and Adair 2019a). However, in recent years these declines have slowed substantially and, as this study shows, are accompanied by substantial and widening socioeconomic and geographical inequalities in risk of death. At ages 35-74, death rates in the lowest area socio-economic quintile are double those in the highest quintile, with the gap widening by over $26 \%$ for females and $14 \%$ for males from 2011-16. A similar trend for females is apparent for other quintiles of socioeconomic status, if less extreme. Populations living in outer regional, remote and 
very remote areas have death rates that are about $40 \%$ higher than in major cities, and the gap has been increasing. Notably, death rates at ages 35-74 among the lowest area socio-economic quintile and outside of major cities have not fallen since 2011. The increase in ASDR ratios by state and remoteness from 2006-16, compared with the national level, has only occurred outside major cities. Even within major cities, there has been a widening in inequalities in death rates between lower and higher area socio-economic deciles, but notably no slowdown in the rate of mortality decline in the highest deciles. Importantly, there was a stagnation in overall mortality rates between 2014-16 at ages 35-74 years, although longer-term trends suggest it is the lowest quintiles that are most affected. At ages less than 35 years, inequalities did not widen to the extent of 35-74 years; they were substantially higher earlier in the period but were only slightly higher in 2016.

The recent widening of mortality inequalities in Australia are a continuation of a similar trend in inequalities in avoidable mortality from 1986 to 2002, however the period covered by this study is typified by vastly slower, and even very recently stagnating, mortality decline than the earlier period (Korda et al. 2007). In this context, the widening of mortality differentials in Australia by socioeconomic group, and by area of residence, should be a matter for immediate policy action. While the causes of death contributing to these unfavourable trends are beyond the scope of this analysis, it is likely that much of the explanation, at least for the socioeconomic differentials, lies with differential risk factor exposure and health behaviours in the various socioeconomic quintile groups. In particular, risk factors such as smoking, alcohol, obesity, diet and fasting plasma glucose levels are the primary drivers of ischaemic heart diseases, diabetes, stroke, cancers, chronic respiratory disease, road traffic accidents and suicide, all of which are among the leading causes of death in Australia (GBD 2017 Causes of Death Collaborators 2018). There is consistent evidence to suggest that these adverse health behaviours are much more prevalent among lower than higher socioeconomic groups of Australian society, with the latter having been the most responsive to health promotion messages about their hazards more than others. For example, smoking prevalence is 2.7 times higher and obesity is 1.6 times higher in the lowest compared with highest socioeconomic group (Australian Institute of Health and Welfare 2018). Improving the efficacy of health promotional campaigns among the lower socioeconomic groups in Australia is clearly important if these inequalities are to be effectively addressed and overall levels of mortality reduced.

For geographic discrepancies in mortality risk, inequalities in access to health care, as well as the availability of essential trauma and acute care services, are likely to also play an important role in the excess mortality risks observed in rural and regional populations, in addition to higher exposure to key risk factors. For example, levels of overweight/obesity, no or low level of physical exercise and lifetime risky alcohol consumption, all important determinants of cardiovascular disease, diabetes, liver cirrhosis and certain forms of cancer, were significantly higher in outer regional and remote populations than in capital cities (Australian Institute of Health and Welfare 2018).

A limitation of this study is that it uses an area-level rather than individual level measure of socioeconomic status. Hence, it is likely that it underestimates the true extent of socioeconomic inequalities in mortality risk. A study of mortality at 20 years and over from 2001-07 showed the relative risk of mortality to be $88 \%$ higher in the lowest versus highest individual income quintile; this is lower than what our analysis found in 2016. However, inequalities have widened since that period and that analysis also included deaths over 75 years, an age where inequalities are not as great as at 
younger ages (Clarke and Leigh 2011, Australian Institute of Health and Welfare 2014). A study comparing mortality at ages 25-84 years by individual education level (not completed Year 12 nor post-secondary education versus Bachelor's degree or higher) showed inequalities to be twice as high among males than females, a large contrast to the similar inequalities by sex found in our study (Korda et al. 2019). This demonstrates how individual measures of inequality can reveal more granular information that area-level measures, in particular the benefits of increased education on mortality risk for males compared with females.

Another issue was there was no consistent measure of area socio-economic quintile from 2006 to 2016. The IRSAD used from 2011-16 showed much larger and increasing inequalities in mortality than the IRSAD used during 2006-10. These differences very likely reflect an improved measure of socioeconomic status, although the increased speed of ASDR ratios in the later period are also highly likely to reflect genuine trends.

\section{Conclusion}

The widening inequalities presented in this study, if they continue, are likely to be a key factor in hampering future life expectancy growth in Australia. These trends are particularly concerning given the significant slowdown in mortality declines at ages 35-74 years in recent years, and the concurrent widening of wealth and income inequalities in Australia. Reducing inequalities in mortality is likely to require a substantial shift in public policy orientation, with much more emphasis on adapting interventions to the socioeconomic context and stressors that are common among the lower socioeconomic groups. These derive from occupation, income, housing, transport, and financial pressures, to name a few, but it is unlikely that reducing their impact on survival will happen quickly. Reducing risk factor exposure among lower socio-economic groups and improved access to secondary prevention and treatment in these groups, and outside of capital cities, is key, but is unlikely to happen unless these broader structural determinants of health that drive individual health behaviour are also addressed.

\section{Key messages}

- Mortality decline in Australia at 35-74 years has slowed substantially in recent years.

- In the poorest area socio-economic quintile, mortality rates stagnated from 2011 to 2016 and inequalities widened compared with the highest quintile.

- Mortality rates outside major cities also were steady from 2011 to 2016 and inequalities also increased compared with major cities.

- Australia's future life expectancy growth will be hindered without further reductions in mortality in the lowest socio-economic groups and outside major cities.

\section{Acknowledgements}

The authors wish to thank the Registries of Births, Deaths and Marriages, the Coroners and the National Coronial Information System for enabling COD URF data to be used for this publication. The authors also wish to acknowledge the assistance of Surender Pandey in assisting with the literature review for this study. This research received no specific grant from any funding agency. 


\section{References}

Adair T, Hoy D, Dettrick Z, and Lopez A D (2011) Reconstruction of long-term tobacco consumption trends in Australia and their relationship to lung cancer mortality. Cancer Causes \& Control 22(7): 10471053.

ABS (2006) Australian Standard Geographic Classification (ASGC), 2006. Catalogue No. 1216.0. Canberra: ABS.

ABS (2008) Census of Population and Housing: Socio-Economic Indexes for Areas (SEIFA), Australia, 2006. Catalogue No. 2033.0.55.001. Canberra: ABS.

ABS (2011) Australian Standard Geographical Classification (ASGC) Remoteness Area Correspondences, 2006. Catalogue No. 1216.0.15.003. Canberra: ABS.

ABS (2013a) Australian Statistical Geography Standard (ASGS): Volume 5 - Remoteness Structure. Catalogue No. 2033.0.55.005. Canberra: ABS.

ABS (2013b) Census of Population and Housing: Socio-Economic Indexes for Areas (SEIFA), Australia, 2011. Catalogue No. 2033.0.55.001. Canberra: ABS.

ABS (2016) Australian Statistical Geography Standard (ASGS): Volume 1 - Main Structure and Greater Capital City Statistical Areas, July 2016. Catalogue No. 1270.0.55.001. Canberra: ABS.

ABS (2018a) Census of Population and Housing: Socio-Economic Indexes for Areas (SEIFA), Australia, 2016. Catalogue No. 2033.0.55.001. Canberra: ABS.

ABS (2018b) Population by Age and Sex, Regions of Australia. Catalogue No. 3235.0. Canberra: ABS.

ABS (2019) Household Income and Wealth, Australia, 2017-18. Catalogue No. 6523.0. Canberra: ABS.

Australian Coordinating Registry (2019) Cause of Death Unit Record File, 2006-17. Brisbane: Australian Coordinating Registry.

Australian Institute of Health and Welfare (2014) Mortality Inequalities in Australia, 2009-11. Catalogue No. AUS 184. Canberra: Australian Institute of Health and Welfare.

Australian Institute of Health and Welfare (2018) Australia's Health 2018. Catalogue No. AUS 221. Canberra: Australian Institute of Health and Welfare.

Case A and Deaton A (2015) Rising morbidity and mortality in midlife among white non-Hispanic Americans in the 21st century. Proceedings of the National Academy of Sciences of the United States of America 112(49): 15078-15083.

Clarke P and Leigh A (2011) Death, dollars and degrees: socio-economic status and longevity in Australia. Economic Papers 30(3): 348-355.

Dewan P, Rorth R, Jhund P S, et al. (2019) Income inequality and outcomes in heart failure: a global between-country analysis. JACC Heart Failure 7(4): 336-346.

Draper G, Turrell G, and Oldenburg B (2004) Health Inequalities in Australia: Mortality. Category No. PHE 55. Canberra: Queensland University of Technology and the Australian Institute of Health and Welfare.

Dwyer-Lindgren L, Bertozzi-Villa A, Stubbs R, et al. (2017) Inequalities in life expectancy among US counties, 1980 to 2014: temporal trends and key drivers. JAMA Internal Medicine 177(7): 10031011.

Fan J and Gijbels I (1996) Local Polynomial Modelling and Its Applications. London: Chapman \& Hall.

GBD 2017 Causes of Death Collaborators (2018) Global, regional, and national age-sex-specific mortality for 282 causes of death in 195 countries and territories, 1980-2017: a systematic analysis for the Global Burden of Disease Study 2017. Lancet 392: 1736-1788.

GBD 2017 Mortality Collaborators (2018) Global, regional, and national age-sex-specific mortality and life expectancy, 1950-2017: a systematic analysis for the Global Burden of Disease Study 2017. Lancet 392: 1684-1735. 
GBD Mortality Collaborators (2017) Global, regional, and national under-5 mortality, adult mortality, agespecific mortality, and life expectancy, 1970-2016: a systematic analysis for the Global Burden of Disease Study 2016. Lancet 390(10100): 1084-1150.

Hayes, A J, Lung T W, Bauman A , and Howard K (2017) Modelling obesity trends in Australia: unravelling the past and predicting the future. International Journal of Obesity 41(1): 178-185.

Korda R J, Biddle N, Lynch J, et al. (2019) Education inequalities in adult all-cause mortality: first national data for Australia using linked census and mortality data. International Journal of Epidemiology dyz191, https://doi.org/10.1093/ije/dyz191.

Korda R J, Butler J R, Clements M S, and Kunitz S J (2007) Differential impacts of health care in Australia: trend analysis of socioeconomic inequalities in avoidable mortality. International Journal of Epidemiology 36(1): 157-165.

Lopez A D and Adair T (2019a) Slower increase in life expectancy in Australia than in other high income countries: the contributions of age and cause of death. Medical Journal of Australia 210(9): 403408.

Lopez A D and Adair T (2019b) Is the long-term decline in cardiovascular-disease mortality in high-income countries over? Evidence from national vital statistics. International Journal of Epidemiology 48(6): 1815-1823.

Norman P, Charles-Edwards E, and Wilson T (2016) Relationships between population change, deprivation change and health change at small area level: Australia 2001-2011. In: Wilson T, Charles-Edwards E, and Bell M (eds) Demography for Planning and Policy: Australian Case Studies. Basel: Springer.

O'Flaherty, M, Allender S, Taylor R, et al. (2012) The decline in coronary heart disease mortality is slowing in young adults (Australia 1976-2006): a time trend analysis. International Journal of Cardiology 158(2): 193-198.

Page A, Lane A, Taylor R, and Dobson A (2012) Trends in socioeconomic inequalities in mortality from ischaemic heart disease and stroke in Australia, 1979-2006. European Journal Preventive Cardiology 19(6): 1281-1289.

StataCorp LP (2017) Stata/SE 15.0. College Station TX: StataCorp LP.

Stephens A S, Gupta L, Thackway S, and Broome R A (2017) Socioeconomic, remoteness and sex differences in life expectancy in New South Wales, Australia, 2001-2012: a population-based study. BMJ Open 7(1): e013227.

Taylor R, Dobson A, and Mirzaei M (2006) Contribution of changes in risk factors to the decline of coronary heart disease mortality in Australia over three decades. European Journal of Cardiovascular Prevention and Rehabilitation 13(5): 760-768.

Taylor R, Page A, and Danquah J (2012) The Australian epidemic of cardiovascular mortality 1935-2005: effects of period and birth cohort. Journal of Epidemiology and Community Health 66(7): e18. 


\section{Appendix}

Table A1: ASDR by sex, remoteness and state and remoteness: annualised change (\%) and ratios, 35-74 years, Australia, 2006-16

\begin{tabular}{|c|c|c|c|c|c|}
\hline \multirow[t]{2}{*}{ Males } & \multicolumn{2}{|c|}{ Annualised change (\%) } & \multicolumn{3}{|c|}{ Ratio to Reference category } \\
\hline & 2006-11 & 2011-16 & 2006 & 2011 & 2016 \\
\hline \multirow[t]{2}{*}{ Australia } & -1.9 & -1.0 & - & - & - \\
\hline & $(-2.3--1.6)$ & $(-1.4--0.6)$ & & & \\
\hline \multicolumn{6}{|l|}{ Remoteness } \\
\hline \multirow[t]{2}{*}{ Major cities } & -1.9 & -1.3 & Ref. & Ref. & Ref. \\
\hline & $(-2.4--1.3)$ & $(-1.8--0.7)$ & & & \\
\hline \multirow[t]{2}{*}{ Inner regional } & -1.8 & -0.2 & 1.12 & 1.12 & 1.19 \\
\hline & $(-2.3--1.2)$ & $(-0.8-+0.4)$ & $(1.08-1.16)$ & $(1.10-1.15)$ & $(1.14-1.23)$ \\
\hline Outer regional/ & -1.4 & -0.2 & 1.31 & 1.34 & 1.41 \\
\hline Remote/ Very remote & $(-1.7--1.0)$ & $(-0.6-+0.1)$ & $(1.27-1.34)$ & $(1.32-1.36)$ & $(1.37-1.45)$ \\
\hline \multicolumn{6}{|l|}{ State and remoteness } \\
\hline \multirow[t]{2}{*}{ NSW Major cities } & -1.8 & -1.2 & 0.94 & 0.95 & 0.94 \\
\hline & $(-2.3--1.2)$ & $(-1.8--0.6)$ & $(0.91-0.97)$ & $(0.93-0.96)$ & $(0.91-0.97)$ \\
\hline \multirow[t]{2}{*}{ NSW Inner regional } & -1.4 & +0.1 & 1.06 & 1.08 & 1.15 \\
\hline & $(-2.4--0.4)$ & $(-1.0-+1.2)$ & $(1.01-1.11)$ & $(1.06-1.11)$ & $(1.09-1.21)$ \\
\hline NSW Outer regional/ & -0.8 & +0.3 & 1.25 & 1.32 & 1.40 \\
\hline Remote/ Very remote & $(-1.5--0.2)$ & $(-0.4-1.0)$ & $(1.20-1.29)$ & $(1.29-1.34)$ & $(1.35-1.46)$ \\
\hline \multirow[t]{2}{*}{ VIC Major cities } & -2.2 & -1.7 & 0.90 & 0.88 & 0.85 \\
\hline & $(-2.8--1.7)$ & $(-2.3--1.0)$ & $(0.87-0.92)$ & $(0.87-0.90)$ & $(0.82-0.88)$ \\
\hline \multirow[t]{2}{*}{ VIC Inner regional } & -2.6 & -0.9 & 1.06 & 1.02 & 1.03 \\
\hline & $(-3.8--1.4)$ & $(-2.2-+0.5)$ & $(1.00-1.12)$ & $(0.99-1.06)$ & $(0.96-1.10)$ \\
\hline VIC Outer regional/ & +0.9 & -2.2 & 1.04 & 1.20 & 1.13 \\
\hline Remote/ Very remote & $(-1.1-+3.0)$ & $(-4.2--0.1)$ & $(0.94-1.14)$ & $(1.14-1.26)$ & $(1.01-1.25)$ \\
\hline \multirow[t]{2}{*}{ QLD Major cities } & -1.6 & -1.3 & 0.93 & 0.95 & 0.93 \\
\hline & $(-2.7--0.4)$ & $(-2.6--0.1)$ & $(0.88-0.98)$ & $(0.92-0.98)$ & $(0.88-0.99)$ \\
\hline \multirow[t]{2}{*}{ QLD Inner regional } & -0.9 & -0.2 & 0.99 & 1.04 & 1.08 \\
\hline & $(-1.7--0.2)$ & $(-1.0-+0.6)$ & $(0.95-1.03)$ & $(1.02-1.06)$ & $(1.04-1.13)$ \\
\hline QLD Outer regional/ & -1.7 & -0.8 & 1.19 & 1.20 & 1.22 \\
\hline Remote/ Very remote & $(-2.6--0.8)$ & $(-1.7-+0.2)$ & $(1.14-1.24)$ & $(1.17-1.23)$ & $(1.16-1.28)$ \\
\hline \multirow[t]{2}{*}{ SA Major cities } & -1.9 & -1.5 & 1.01 & 1.01 & 0.98 \\
\hline & $(-2.8--0.9)$ & $(-2.5--0.4)$ & $(0.96-1.05)$ & $(0.98-1.03)$ & $(0.93-1.04)$ \\
\hline \multirow[t]{2}{*}{ SA Other } & -1.2 & +1.0 & 1.03 & 1.07 & 1.18 \\
\hline & $(-2.3--0.2)$ & $(0.0-2.1)$ & $(0.98-1.08)$ & $(1.04-1.10)$ & $(1.12-1.25)$ \\
\hline \multirow[t]{2}{*}{ WA Major cities } & -1.4 & -0.5 & 0.89 & 0.91 & 0.93 \\
\hline & $(-2.1--0.7)$ & $(-1.2-+0.3)$ & $(0.86-0.92)$ & $(0.89-0.93)$ & $(0.9-0.97)$ \\
\hline \multirow[t]{2}{*}{ WA Other } & -1.6 & +0.4 & 1.04 & 1.06 & 1.14 \\
\hline & $(-2.7--0.4)$ & $(-0.8-+1.7)$ & $(0.98-1.10)$ & $(1.03-1.09)$ & $(1.07-1.21)$ \\
\hline \multirow[t]{2}{*}{ TAS } & -1.9 & +0.4 & 1.14 & 1.14 & 1.23 \\
\hline & $(-3.1--0.7)$ & $(-0.8-+1.7)$ & $(1.08-1.21)$ & $(1.11-1.18)$ & $(1.15-1.30)$ \\
\hline \multirow[t]{2}{*}{ NT } & -5.0 & -1.9 & 1.94 & 1.65 & 1.58 \\
\hline & $(-6.3--3.6)$ & $(-3.6--0.3)$ & $(1.79-2.09)$ & $(1.58-1.73)$ & $(1.43-1.74)$ \\
\hline \multirow[t]{2}{*}{ ACT } & -2.7 & 0.2 & 0.85 & 0.81 & 0.86 \\
\hline & $(-4.6--0.8)$ & $(-1.9-+2.4)$ & $(0.78-0.92)$ & $(0.78-0.85)$ & $(0.79-0.95)$ \\
\hline
\end{tabular}


Table A1 continued

\begin{tabular}{|c|c|c|c|c|c|}
\hline \multirow{2}{*}{$\begin{array}{l}\text { Females } \\
\text { Australia }\end{array}$} & \multicolumn{2}{|c|}{ Annualised change (\%) } & \multicolumn{3}{|c|}{ Ratio to Reference category } \\
\hline & $\begin{array}{r}-1.6 \\
(-2.0--1.2)\end{array}$ & $\begin{array}{r}-1.0 \\
(-1.4--0.6)\end{array}$ & - & - & - \\
\hline \multicolumn{6}{|l|}{ Remoteness } \\
\hline Major cities & $\begin{array}{r}-1.8 \\
(-2.1--1.5)\end{array}$ & $\begin{array}{r}-1.4 \\
(-1.7--1.1)\end{array}$ & Ref. & & Ref. \\
\hline Inner regional & $\begin{array}{r}-0.8 \\
(-1.8-+0.1)\end{array}$ & $\begin{array}{r}+0.1 \\
(-0.9-+1.1)\end{array}$ & $\begin{array}{r}1.07 \\
(1.02-1.12)\end{array}$ & $\begin{array}{r}1.13 \\
(1.10-1.16)\end{array}$ & $\begin{array}{r}1.22 \\
(1.16-1.28)\end{array}$ \\
\hline $\begin{array}{l}\text { Outer regional/ } \\
\text { Remote/ Very remote }\end{array}$ & $\begin{array}{r}-1.0 \\
(-1.9--0.1)\end{array}$ & $\begin{array}{r}-0.4 \\
(-1.3-+0.6)\end{array}$ & $\begin{array}{r}1.28 \\
(1.22-1.34)\end{array}$ & $\begin{array}{r}1.33 \\
(1.30-1.36)\end{array}$ & $\begin{array}{r}1.40 \\
(1.33-1.48)\end{array}$ \\
\hline \multicolumn{6}{|l|}{ State and remoteness } \\
\hline NSW Major cities & $\begin{array}{r}-1.9 \\
(-2.3--1.5)\end{array}$ & $\begin{array}{r}-1.8 \\
(-2.2--1.3)\end{array}$ & $\begin{array}{r}0.96 \\
(0.94-0.98)\end{array}$ & $\begin{array}{r}0.95 \\
(0.94-0.96)\end{array}$ & $\begin{array}{r}0.91 \\
(0.89-0.94)\end{array}$ \\
\hline NSW Inner regional & $\begin{array}{r}-0.3 \\
(-2-1.5)\end{array}$ & $\begin{array}{r}-0.5 \\
(-2.2-+1.3)\end{array}$ & $\begin{array}{r}1.02 \\
(0.94-1.10)\end{array}$ & $\begin{array}{r}1.09 \\
(1.05-1.14)\end{array}$ & $\begin{array}{r}1.12 \\
(1.03-1.22)\end{array}$ \\
\hline $\begin{array}{l}\text { NSW Outer regional/ } \\
\text { Remote/ Very remote }\end{array}$ & $\begin{array}{r}-1.5 \\
(-3.4-+0.3)\end{array}$ & $\begin{array}{r}0.1 \\
(-1.8-+2.0)\end{array}$ & $\begin{array}{r}1.25 \\
(1.14-1.37)\end{array}$ & $\begin{array}{r}1.26 \\
(1.20-1.32)\end{array}$ & $\begin{array}{r}1.33 \\
(1.20-1.47)\end{array}$ \\
\hline VIC Major cities & $\begin{array}{r}-2.7 \\
(-3.3--2.0)\end{array}$ & $\begin{array}{r}-0.9 \\
(-1.6--0.3)\end{array}$ & $\begin{array}{r}0.93 \\
(0.90-0.96)\end{array}$ & $\begin{array}{r}0.89 \\
(0.87-0.90)\end{array}$ & $\begin{array}{r}0.89 \\
(0.86-0.92)\end{array}$ \\
\hline VIC Inner regional & $\begin{array}{r}-0.4 \\
(-1.5-+0.8)\end{array}$ & $\begin{array}{r}-0.1 \\
(-1.3-+1.0)\end{array}$ & $\begin{array}{r}1.00 \\
(0.95-1.06)\end{array}$ & $\begin{array}{r}1.07 \\
(1.04-1.10)\end{array}$ & $\begin{array}{r}1.12 \\
(1.05-1.18)\end{array}$ \\
\hline $\begin{array}{l}\text { VIC Outer regional/ } \\
\text { Remote/ Very remote }\end{array}$ & $\begin{array}{r}-0.8 \\
(-1.9-+0.3)\end{array}$ & $\begin{array}{r}+0.5 \\
(-0.6-+1.7)\end{array}$ & $\begin{array}{r}1.03 \\
(0.98-1.08)\end{array}$ & $\begin{array}{r}1.07 \\
(1.04-1.10)\end{array}$ & $\begin{array}{r}1.16 \\
(1.10-1.23)\end{array}$ \\
\hline QLD Major cities & $\begin{array}{r}-1.4 \\
(-1.7--1.1)\end{array}$ & $\begin{array}{r}-1.7 \\
(-2.1--1.4)\end{array}$ & $\begin{array}{r}0.95 \\
(0.93-0.97)\end{array}$ & $\begin{array}{r}0.96 \\
(0.95-0.97)\end{array}$ & $\begin{array}{r}0.92 \\
(0.9-0.95)\end{array}$ \\
\hline QLD Inner regional & $\begin{array}{r}-1.0 \\
(-2.4-+0.3)\end{array}$ & $\begin{array}{r}+1.2 \\
(-0.2-+2.5)\end{array}$ & $\begin{array}{r}0.96 \\
(0.91-1.02)\end{array}$ & $\begin{array}{r}0.99 \\
(0.96-1.02)\end{array}$ & $\begin{array}{r}1.10 \\
(1.04-1.18)\end{array}$ \\
\hline $\begin{array}{l}\text { QLD Outer regional/ } \\
\text { Remote/ Very remote }\end{array}$ & $\begin{array}{r}-0.5 \\
(-2.4-1.6)\end{array}$ & $\begin{array}{r}-1.5 \\
(-3.5-+0.6)\end{array}$ & $\begin{array}{r}1.13 \\
(1.03-1.25)\end{array}$ & $\begin{array}{r}1.20 \\
(1.14-1.27)\end{array}$ & $\begin{array}{r}1.18 \\
(1.06-1.31)\end{array}$ \\
\hline SA Major cities & $\begin{array}{r}+0.1 \\
(-0.7-+1.0)\end{array}$ & $\begin{array}{r}-1.8 \\
(-2.7--1.0)\end{array}$ & $\begin{array}{r}0.95 \\
(0.92-0.99)\end{array}$ & $\begin{array}{r}1.04 \\
(1.02-1.06)\end{array}$ & $\begin{array}{r}1.00 \\
(0.95-1.05)\end{array}$ \\
\hline SA Other & $\begin{array}{r}-2.3 \\
(-4.2--0.4)\end{array}$ & $\begin{array}{r}-0.6 \\
(-2.6-+1.5)\end{array}$ & $\begin{array}{r}1.08 \\
(0.99-1.17)\end{array}$ & $\begin{array}{r}1.04 \\
(0.99-1.09)\end{array}$ & $\begin{array}{r}1.06 \\
(0.96-1.17)\end{array}$ \\
\hline WA Major cities & $\begin{array}{r}-1.9 \\
(-3.3--0.4)\end{array}$ & $\begin{array}{r}-0.9 \\
(-2.4-0.7)\end{array}$ & $\begin{array}{r}0.91 \\
(0.85-0.97)\end{array}$ & $\begin{array}{r}0.90 \\
(0.87-0.93)\end{array}$ & $\begin{array}{r}0.90 \\
(0.84-0.97)\end{array}$ \\
\hline WA Other & $\begin{array}{r}-2.7 \\
(-5.0--0.3)\end{array}$ & $\begin{array}{r}+0.8 \\
(-1.7-+3.5)\end{array}$ & $\begin{array}{r}1.11 \\
(1.00-1.24)\end{array}$ & $\begin{array}{r}1.05 \\
(0.99-1.12)\end{array}$ & $\begin{array}{r}1.16 \\
(1.03-1.31)\end{array}$ \\
\hline TAS & $\begin{array}{r}-0.2 \\
(-1.8-+1.4)\end{array}$ & $\begin{array}{r}-0.4 \\
(-2.0-+1.2)\end{array}$ & $\begin{array}{r}1.17 \\
(1.08-1.27)\end{array}$ & $\begin{array}{r}1.26 \\
(1.21-1.31)\end{array}$ & $\begin{array}{r}1.30 \\
(1.19-1.41)\end{array}$ \\
\hline NT & $\begin{array}{r}-0.8 \\
(-3.5-+1.9)\end{array}$ & $\begin{array}{r}0.0 \\
(-2.8-+2.8)\end{array}$ & $\begin{array}{r}1.84 \\
(1.57-2.15)\end{array}$ & $\begin{array}{r}1.91 \\
(1.76-2.09)\end{array}$ & $\begin{array}{r}2.01 \\
(1.69-2.39)\end{array}$ \\
\hline ACT & $\begin{array}{r}-2.2 \\
(-4.0--0.4)\end{array}$ & $\begin{array}{r}0.0 \\
(-1.9-+2.0)\end{array}$ & $\begin{array}{r}0.90 \\
(0.84-0.97)\end{array}$ & $\begin{array}{r}0.88 \\
(0.84-0.92)\end{array}$ & $\begin{array}{r}0.92 \\
(0.85-1.01)\end{array}$ \\
\hline
\end{tabular}

Notes. Ref.: Reference category. 
Table A2: ASDR by sex, area socio-economic quintile and major cities area socio-economic decile group: annualised change (\%) and ratios, 35-74 years, Australia, 2006-10 and 2011-16

\begin{tabular}{|c|c|c|c|c|c|c|}
\hline \multirow[t]{2}{*}{ Males } & \multicolumn{2}{|c|}{ Annualised change (\%) } & \multicolumn{4}{|c|}{ Ratio to Reference category } \\
\hline & 2006-10 & 2011-16 & 2006 & 2010 & 2011 & 2016 \\
\hline \multicolumn{7}{|c|}{ Area socio-economic quintile } \\
\hline \multirow[t]{2}{*}{ Q1 (Lowest) } & -1.5 & +0.2 & 1.62 & 1.62 & 1.97 & 2.11 \\
\hline & $(-2.4--0.6)$ & $(-0.3-0.8)$ & $(1.56-1.68)$ & $(1.56-1.69)$ & $(1.91-2.03)$ & $(2.04-2.17)$ \\
\hline \multirow[t]{2}{*}{ Q2 } & -2.6 & -1.0 & 1.48 & 1.42 & 1.69 & 1.70 \\
\hline & $(-3.7--1.6)$ & $(-1.5--0.4)$ & $(1.43-1.54)$ & $(1.36-1.48)$ & $(1.64-1.74)$ & $(1.65-1.75)$ \\
\hline \multirow[t]{2}{*}{ Q3 } & -3.2 & -1.1 & 1.41 & 1.31 & 1.46 & 1.46 \\
\hline & $(-4.0--2.4)$ & $(-2.4-+0.2)$ & $(1.36-1.45)$ & $(1.27-1.36)$ & $(1.38-1.55)$ & $(1.38-1.55)$ \\
\hline \multirow[t]{2}{*}{ Q4 } & -0.1 & -1.5 & 1.12 & 1.19 & 1.27 & 1.25 \\
\hline & $(-3.0-2.9)$ & $(-2.1--0.9)$ & $(1.02-1.22)$ & $(1.08-1.3)$ & $(1.24-1.31)$ & $(1.21-1.29)$ \\
\hline \multirow[t]{2}{*}{ Q5 (Highest) } & -1.6 & -1.1 & Ref. & Ref. & Ref. & Ref. \\
\hline & $(-2.3--0.8)$ & $(-1.6--0.5)$ & & & & \\
\hline \multicolumn{7}{|c|}{ Major cities Area socio-economic decile group } \\
\hline \multirow[t]{2}{*}{$1-4$} & -1.9 & -0.5 & 1.49 & 1.45 & 1.70 & 1.79 \\
\hline & $(-3.0--0.8)$ & $(-1.3-+0.3)$ & $(1.42-1.57)$ & $(1.37-1.53)$ & $(1.63-1.77)$ & $(1.71-1.87)$ \\
\hline \multirow[t]{2}{*}{$5-7$} & -2.5 & -1.3 & 1.31 & 1.24 & 1.33 & 1.34 \\
\hline & $(-2.8--2.2)$ & $(-2.4--0.3)$ & $(1.26-1.36)$ & $(1.19-1.30)$ & $(1.27-1.39)$ & $(1.27-1.40)$ \\
\hline \multirow[t]{2}{*}{$8-10$} & -1.2 & -1.5 & Ref. & Ref. & Ref. & Ref. \\
\hline & $(-2.8-+0.3)$ & $(-2.2--0.8)$ & & & & \\
\hline \multirow{2}{*}{ Females } & \multicolumn{2}{|c|}{ Annualised change (\%) } & \multicolumn{4}{|c|}{ Ratio to Reference Category } \\
\hline & $2006-10$ & 2011-16 & 2006 & 2010 & 2011 & 2016 \\
\hline \multicolumn{7}{|c|}{ Area socio-economic quintile } \\
\hline \multirow[t]{2}{*}{ Q1 (Lowest) } & -1.8 & 0.0 & 1.49 & 1.57 & 1.78 & 1.98 \\
\hline & $(-3--0.6)$ & $(-0.5-+0.5)$ & $(1.42-1.57)$ & $(1.49-1.66)$ & $(1.74-1.83)$ & $(1.93-2.04)$ \\
\hline \multirow[t]{2}{*}{ Q2 } & -1.3 & -0.4 & 1.35 & 1.46 & 1.51 & 1.65 \\
\hline & $(-2.7-+0.2)$ & $(-1.1-+0.3)$ & $(1.28-1.43)$ & $(1.37-1.55)$ & $(1.46-1.57)$ & $(1.59-1.71)$ \\
\hline \multirow[t]{2}{*}{ Q3 } & -3.2 & -1.1 & 1.31 & 1.3 & 1.34 & 1.41 \\
\hline & $(-4.3--2.2)$ & $(-1.8--0.4)$ & $(1.25-1.36)$ & $(1.24-1.37)$ & $(1.30-1.38)$ & $(1.36-1.46)$ \\
\hline \multirow[t]{2}{*}{ Q4 } & -0.3 & -2.0 & 1.07 & 1.20 & 1.21 & 1.22 \\
\hline & $(-2.6-+2.1)$ & $(-2.7--1.2)$ & $(0.99-1.16)$ & $(1.11-1.31)$ & $(1.17-1.25)$ & $(1.18-1.27)$ \\
\hline \multirow[t]{2}{*}{ Q5 (Highest) } & -3.1 & -2.1 & Ref. & Ref. & Ref. & Ref. \\
\hline & $(-4.3--2.0)$ & $(-2.7--1.6)$ & & & & \\
\hline \multicolumn{7}{|c|}{ Major cities Area socio-economic decile group } \\
\hline \multirow[t]{2}{*}{$1-4$} & -1.3 & -0.6 & 1.40 & 1.41 & 1.58 & 1.72 \\
\hline & $(-2.5-0.0)$ & $(-1.2-0.0)$ & $(1.33-1.47)$ & $(1.34-1.49)$ & $(1.53-1.62)$ & $(1.67-1.77)$ \\
\hline \multirow[t]{2}{*}{$5-7$} & -3.3 & -1.2 & 1.26 & 1.18 & 1.25 & 1.32 \\
\hline & $(-4.2--2.4)$ & $(-2.0--0.4)$ & $(1.22-1.32)$ & $(1.13-1.23)$ & $(1.21-1.29)$ & $(1.27-1.37)$ \\
\hline \multirow[t]{2}{*}{$8-10$} & -1.6 & -2.3 & Ref. & Ref. & Ref. & Ref. \\
\hline & $(-2.7--0.4)$ & $(-2.7--1.9)$ & & & & \\
\hline
\end{tabular}

Notes. 2006 and 2010 measured using IRSAD 2006, 2011 and 2016 measured using IRSAD 2016. 2006 and 2010 results cannot be directly compared with 2011 and 2016 results. Ref.: Reference category. 
Table A3: ASDR by sex and remoteness: annualised change (\%) and ratios, 0-34 years, Australia, 2006-16

\begin{tabular}{|c|c|c|c|c|c|}
\hline \multirow[t]{2}{*}{ Males } & \multicolumn{2}{|c|}{ Annualised change (\%) } & \multicolumn{3}{|c|}{ Ratio to Reference category } \\
\hline & 2006-11 & 2011-16 & 2006 & 2011 & 2016 \\
\hline Australia & $\begin{array}{r}-3.6 \\
(-4.1--3.1)\end{array}$ & $\begin{array}{r}-2.2 \\
(-2.8--1.6)\end{array}$ & - & - & - \\
\hline Major cities & $\begin{array}{r}-3.1 \\
(-4.0--2.3)\end{array}$ & $\begin{array}{r}-1.8 \\
(-2.8--0.9)\end{array}$ & Ref. & Ref. & Ref. \\
\hline Inner regional & $\begin{array}{r}-3.4 \\
(-5.2--1.5)\end{array}$ & $\begin{array}{r}-1.1 \\
(-3.2-+1.0)\end{array}$ & $\begin{array}{r}1.46 \\
(1.33-1.61)\end{array}$ & $\begin{array}{r}1.45 \\
(1.36-1.53)\end{array}$ & $\begin{array}{r}1.50 \\
(1.32-1.70)\end{array}$ \\
\hline $\begin{array}{l}\text { Outer regional/ Remote/ } \\
\text { Very remote }\end{array}$ & $\begin{array}{r}-5.0 \\
(-6.9--3.0)\end{array}$ & $\begin{array}{r}-2.1 \\
(-4.5-+0.3)\end{array}$ & $\begin{array}{r}2.00 \\
(1.79-2.24)\end{array}$ & $\begin{array}{r}1.82 \\
(1.69-1.95)\end{array}$ & $\begin{array}{r}1.79 \\
(1.53-2.09)\end{array}$ \\
\hline Females & \multicolumn{2}{|c|}{ Annualised change (\%) } & \multicolumn{3}{|c|}{ Ratio to Reference category } \\
\hline Australia & $\begin{array}{r}-3.2 \\
(-4.1--2.4)\end{array}$ & $\begin{array}{r}-2.9 \\
(-3.9--2.0)\end{array}$ & - & - & - \\
\hline Major cities & $\begin{array}{r}-3.9 \\
(-4.7--3.1)\end{array}$ & $\begin{array}{r}-3.3 \\
(-4.2--2.4)\end{array}$ & Ref. & & Ref. \\
\hline Inner regional & $\begin{array}{r}-1.9 \\
(-4.0-+0.2)\end{array}$ & $\begin{array}{r}-0.7 \\
(-3.0-+1.6)\end{array}$ & $\begin{array}{r}1.25 \\
(1.12-1.39)\end{array}$ & $\begin{array}{r}1.38 \\
(1.3-1.47)\end{array}$ & $\begin{array}{r}1.58 \\
(1.38-1.80)\end{array}$ \\
\hline $\begin{array}{l}\text { Outer regional/ Remote/ } \\
\text { Very remote }\end{array}$ & $\begin{array}{r}-1.3 \\
(-3.0-+0.5)\end{array}$ & $\begin{array}{r}-1.8 \\
(-3.7-+0.1)\end{array}$ & $\begin{array}{r}1.65 \\
(1.49-1.82)\end{array}$ & $\begin{array}{r}1.89 \\
(1.78-2.00)\end{array}$ & $\begin{array}{r}2.04 \\
(1.80-2.32)\end{array}$ \\
\hline
\end{tabular}

Notes. Ref.: Reference category. 
Table A4: ASDR by sex and area socio-economic quintile: annualised change (\%) and ratios, 0-34 years, Australia, 2006-10 and 2011-16

\begin{tabular}{|c|c|c|c|c|c|c|}
\hline \multirow[t]{2}{*}{ Males } & \multicolumn{2}{|c|}{ Annualised change (\%) } & \multicolumn{4}{|c|}{ Ratio to Reference category } \\
\hline & 2006-10 & 2011-16 & 2006 & 2010 & 2011 & 2016 \\
\hline Q1 & -4.8 & -2.3 & 2.06 & 1.89 & 2.20 & 2.02 \\
\hline (Lowest) & $(-5.6--4.0)$ & $(-4.2--0.4)$ & $(1.94-2.18)$ & $(1.77-2.02)$ & $(1.96-2.48)$ & $(1.77-2.29)$ \\
\hline \multirow[t]{2}{*}{ Q2 } & -2.9 & -2.4 & 1.57 & 1.57 & 1.88 & 1.71 \\
\hline & $(-4.4--1.3)$ & $(-4.7--0.1)$ & $(1.46-1.7)$ & $(1.43-1.71)$ & $(1.65-2.14)$ & $(1.49-1.97)$ \\
\hline \multirow[t]{2}{*}{ Q3 } & -3.3 & -3.1 & 1.46 & 1.43 & 1.49 & 1.32 \\
\hline & $(-5.1--1.5)$ & $(-4.8--1.3)$ & $(1.35-1.59)$ & $(1.30-1.58)$ & $(1.33-1.68)$ & $(1.16-1.49)$ \\
\hline \multirow[t]{2}{*}{ Q4 } & -3.0 & -1.8 & 1.17 & 1.15 & 1.25 & 1.17 \\
\hline & $(-8.3-2.5)$ & $(-4.8-+1.2)$ & $(0.98-1.39)$ & $(0.95-1.40)$ & $(1.07-1.45)$ & $(0.99-1.38)$ \\
\hline \multirow{2}{*}{$\begin{array}{l}\text { Q5 } \\
\text { (Highest) }\end{array}$} & -2.8 & -0.6 & Ref. & Ref. & Ref. & Ref. \\
\hline & $(-5.4--0.1)$ & $(-3.7-+2.6)$ & & & & \\
\hline \multirow{2}{*}{ Females } & \multicolumn{2}{|c|}{ Annualised change (\%) } & \multicolumn{4}{|c|}{ Ratio to Reference Category } \\
\hline & 2006-10 & 2011-16 & 2006 & 2010 & 2011 & 2016 \\
\hline Q1 & -1.6 & -2.7 & 1.85 & 1.89 & 2.11 & 2.18 \\
\hline (Lowest) & $(-3.7-+0.5)$ & $(-5.3--0.1)$ & $(1.68-2.04)$ & $(1.7-2.10)$ & $(1.86-2.39)$ & $(1.88-2.53)$ \\
\hline \multirow[t]{2}{*}{ Q2 } & -3.3 & -2.3 & 1.61 & 1.54 & 1.66 & 1.75 \\
\hline & $(-4.3--2.2)$ & $(-3.9--0.7)$ & $(1.5-1.73)$ & $(1.43-1.67)$ & $(1.54-1.78)$ & $(1.61-1.91)$ \\
\hline \multirow[t]{2}{*}{ Q3 } & -7.0 & -4.5 & 1.56 & 1.28 & 1.55 & 1.46 \\
\hline & $(-8.6--5.5)$ & $(-7.4--1.6)$ & $(1.44-1.69)$ & $(1.16-1.41)$ & $(1.37-1.75)$ & $(1.25-1.69)$ \\
\hline \multirow[t]{2}{*}{ Q4 } & -6.7 & -0.8 & 1.26 & 1.04 & 1.14 & 1.30 \\
\hline & $(-11.7--1.3)$ & $(-3.7-+2.2)$ & $(1.06-1.49)$ & $(0.85-1.28)$ & $(1.02-1.28)$ & $(1.15-1.48)$ \\
\hline Q5 & -2.2 & -3.4 & Ref. & Ref. & Ref. & Ref. \\
\hline (Highest) & $(-5.0-+0.7)$ & $(-4.3--2.4)$ & & & & \\
\hline
\end{tabular}

Notes. 2006 and 2010 measured using IRSAD 2006, 2011 and 2016 measured using IRSAD 2016. 2006 and 2010 results cannot be directly compared with 2011 and 2016 results. Ref.: Reference category. 